\title{
LUDICIDADE E FORMAÇÃO DA \\ CRIANÇA NO PRIMEIRO ANO \\ DO ENSINO FUNDAMENTAL
}

\section{Lucia Helena Pena Pereira \\ Patrícia Vieira Bonfim ${ }^{2}$}

\section{Resumo}

No intuito de analisar os desafios enfrentados pela criança de seis anos ao ingressar no Ensino Fundamental, este artigo apresenta alguns dos resultados de uma pesquisa realizada em escolas públicas de uma cidade mineira. O referencial teórico baseou-se em literatura que considera as atividades lúdicas como aquelas que possibilitam o envolvimento pleno e criativo da criança, favorecendo o seu desenvolvimento integral. Os resultados permitiram apontar que o brincar e o aprender são vistos como açóes opostas na escola; há muitas dúvidas da comunidade quanto à ampliação do ensino obrigatório brasileiro e de como atuar nos anos iniciais, e que, cada vez mais, o lúdico tem ficado em plano secundário nas práticas pedagógicas.

Palavras-chave: Ludicidade; Formação Integral da Criança; Ensino Fundamental de Nove Anos.

1 Lucia Helena Pena Pereira - Universidade Federal de São João del-Rei (DECED/UFSJ).

E-mail: luciahelenapp@gmail.com

2 Patrícia Vieira Bonfim - Instituto Federal de Educação, Ciência e Tecnologia do Sudeste de Minas Gerais.

E-mail: pattycular@yahoo.com.br 


\title{
PLAYFULNESS AND EDUCATION OF CHILDREN IN THE FIRST GRADE OF ELEMENTARY SCHOOL
}

\begin{abstract}
In order to examine the challenges faced by the six years old child when she ingresses in Basic School, this paper presents some of the results of a research accomplished in public state schools of a city of Minas Gerais. The theoretical referential was based in literature which considers the ludic activities as the ones which enables the complete and creative involvement of the child, favoring her full development. The results allow to point which the playing and the learning are seen as opposite actions in school; there are many doubts of the community about the application of Brazilian obligatory teaching and how to act in the initial years, and that, more and more, the ludic have been considered as second plane in pedagogical practices.
\end{abstract}

Keywords: Ludicity; Full Child Formation; Basic School of Nine Years. 


\section{LUDICIDADE E FORMAÇÁO DA \\ CRIANÇA NO PRIMEIRO ANO DO ENSINO FUNDAMENTAL}

As instituições que ofertam o Ensino Fundamental devem passar por reformulaçóes técnico-estruturais e pedagógicas para receber as crianças de seis anos, tendo em vista que a Lei $\mathrm{n}^{\circ} 11.274 / 2006$ foi aprovada e o ensino obrigatório no Brasil passou de oito para nove anos de duração. Consequentemente, ampliou-se o número de vagas no Ensino Fundamental, de modo que, as crianças de seis anos que não estavam na escola pudessem ser matriculadas.

A ampliação do ensino obrigatório no Brasilveio cumprir o que já fora sinalizado há mais de uma década pela Lei de Diretrizes e Bases da Educação Nacional no 9.394/96, como também nivelar uma defasagem de escolarização obrigatória em relação à maioria dos países latino-americanos.

A reestruturação da Educação Básica suscitou muitos questionamentos e problematizaçóes no que tange à formação dos professores, aos currículos, aos tempos-espaços destinados ao lúdico, à gestão democrática, dentre outros. Dada a urgência de estudos e pesquisas que contemplem a ampliação do ensino obrigatório no Brasil, esse estudo justifica-se pelo momento de transitoriedade e incerteza que muitas escolas têm vivido ao implementar essa política em seu cotidiano.

Investigar a prática pedagógica de professores que atuam no primeiro ano do Ensino Fundamental pode contribuir para mapear, apontar e discutir os prováveis descompassos entre o que é anunciado na legislação e em outros documentos oficiais, com o que é encontrado no interior do cotidiano das escolas.

Levantando hipóteses de que o ingresso da criança de seis anos no Ensino Fundamental venha acelerar ou reduzir os
Ludicidade e

formação da criança

no primeiro ano do

ensino fundamenta
Educ. Foco,

Juiz de Fora,

217 v. 20, n. 3, p. 215-236, nov. 2015 / fev. 2016 
tempos da infância, o foco desta pesquisa foi analisar se e como o lúdico ${ }^{3}$ e as atividades expressivas são considerados na escola.

O presente texto é fruto da pesquisa de mestrado realizada em uma cidade do interior mineiro, defendida recentemente. Teve como espaços de investigaçáo três turmas do primeiro ano do Ensino Fundamental, de duas escolas públicas da rede estadual de ensino.

Inicialmente, destacam-se no texto apontamentos teóricos do campo da ludicidade para, em seguida, trazer essas discussóes para o contexto da prática pedagógica e, mais especificamente, para o primeiro ano do Ensino Fundamental. $\mathrm{O}$ texto dialoga com autores da área e alguns dados da pesquisa de campo, como fragmentos das entrevistas com as professores e registros extraídos do diário de campo sobre situaçóes observadas na prática pedagógica e nas interaçóes criança-criança e criança-adulto.

\section{DESTACANDO CONCEITOS}

Cipriano Carlos Luckesi, respeitado pesquisador da educação, se dedicou por muito tempo aos estudos de avaliação educacional e de outros temas vinculados à prática pedagógica como o currículo, a transdisciplinaridade, a didática e a formação de professores. A partir do final do século XX, o autor vem se dedicando, também, aos conceitos e vivências do lúdico, discussóes essas germinadas no Grupo de Estudos e Pesquisas em Educação e Ludicidade (GEPEL), criado em 1999, vinculado ao Programa de Pós-Graduação em Educação da Universidade Federal da Bahia, em Salvador, focando seus estudos nas conceituaçóes sobre o lúdico, nos objetos lúdicos, nas instituiçóes que trabalham com a ludicidade e nos pesquisadores engajados com o tema.

3 Neste artigo, lúdico, ludicidade e atividades lúdicas apresentam a mesma conotação. 
Ao se referir à ludicidade, Luckesi (2002) argumenta que esta abrange um ponto de vista interno e integral; interno, porque se trata, na sua concepçáo, da experiência subjetiva do indivíduo que a vivencia; integral, porque compreende essa dimensão subjetiva indissociável da vida exterior e de suas relações sociais, culturais e históricas. Na visão do autor, a ludicidade deve ser vivenciada no aqui e agora e não com o objetivo de os resultados serem a fonte motivadora da proposta.

Na mesma linha de discussão, Olivier (2003) afirma o quanto as pessoas estáo acostumadas a viver mais para o futuro do que para o presente. Preocupam-se com o que vão fazer depois da aula, depois da graduação, depois da estabilidade financeira, depois da aposentadoria, depois de amanhā... Mas como fica o hoje? E as atividades diárias, sáo vividas integral e intensamente ou realizadas apenas para cumprir obrigaçôes?

Esse é um dos conflitos percebidos nos tempos-espaços da escola por meio de ensinamentos, às vezes não-intencionais, que levam os educandos a viverem em função do futuro: fazer boas provas para passar de ano; estudar para ter um bom emprego; ou ainda, em relação à criança, fazer a tarefas bem rápido para ampliar-se o tempo de brincadeira!

Por meio dessas frases de efeito, a criança se conforma sempre com o depois; e passa despercebido que o mais importante é o prazer que a aprendizagem possibilita ao conhecermos algo novo, estar de corpo e mente na atividade vivida, o que Luckesi (2002) denomina como perspectiva interna da ludicidade.

$\mathrm{Na}$ atividade lúdica, a criança desfruta intensamente do momento presente sem se preocupar com recompensas e resultados. Por isso, Kishimoto (2009) insiste que o brincar livre e espontâneo é uma vivência lúdica, enquanto que fazê-lo num contexto pedagógico nem sempre o será.

$\mathrm{Na}$ concepçáo de ludicidade adotada, os brinquedos e outros objetos que dáo suporte aos jogos e brincadeiras não

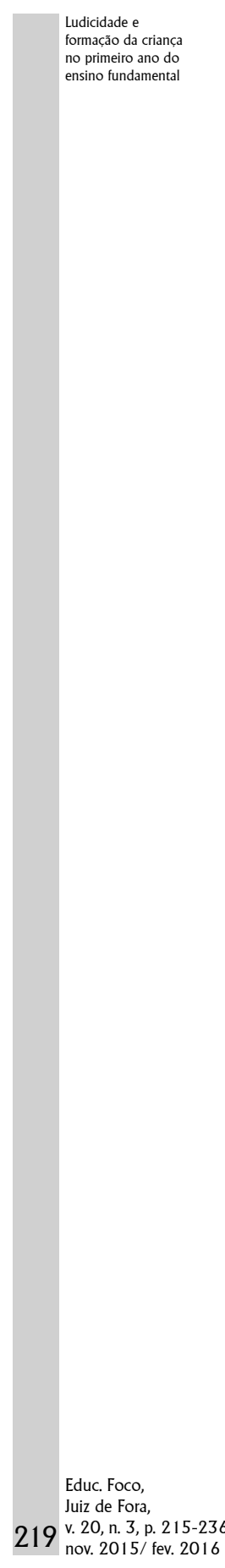


sấo os elementos potencializadores, e sim o corpo. Por meio dele, é possível criar inúmeras possibilidades, como:

Uma brincadeira, um jogo ou qualquer outra atividade que possibilite instaurar um estado de inteireza: uma dinâmica de integração grupal ou de sensibilizaçáo, atividades de artes plásticas (massa de modelar, recorte e colagem, desenhos, pinturas, construçáo de fantoches), uma das muitas expressóes dos jogos dramáticos, exercícios de relaxamento e respiraçāo, uma ciranda, atividades rítmicas, entre outras. Mais importante, porém, do que o tipo de atividade é a forma como é orientada e como é experienciada, e o porquê de estar sendo realizada. Ela deve permitir que cada um possa se expressar livre e solidariamente, unindo razão e emoção (PEREIRA, 2006, p. 12).

A vivência da ludicidade proporciona a integração movimento-emoçáo-cognição e o envolvimento profundo do ser humano com a atividade realizada. Para a execução de qualquer atividade lúdica na escola, são necessários o planejamento, a responsabilidade e o comprometimento do professor. É pouco provável que a criança vivencie verdadeiramente a ludicidade se o professor: apenas lhe permite brincar nos últimos minutos de aula; ausenta-se da sala após propor uma atividade lúdica; ou a utiliza quando não há planejamento dos conteúdos disciplinares, conforme aponta a professora Margarida ao ser questionada sobre em que momentos trabalha a ludicidade em sala de aula.

Eu trabalho mais no final do tempo, mais final da semana, final do tempo, dependendo de como está a turma. Se ela está muito agitada, aí eu acho que cabe um canto, uma brincadeira. Uma música para mexer com os pés, com as mãos, dar gargalhadas. Eu acho que isso relaxa o menino também. No momento da agitação a gente pode aproveitar para propor uma atividade dessas (Fragmentos da Entrevista). 
Em vários momentos da pesquisa de campo foi observado que a atividade lúdica se insere em segundo plano na prática pedagógica, descaracterizando, assim, suas reais potencialidades, de permitir à criança criar, brincar, dramatizar, cantar, dançar, utilizar as fontes sensoriais e perceptivas e, assim, fazer da ludicidade um encontro possível na prática pedagógica.

\section{A LUDICIDADE NA PRÁTICA PEDAGÓGICA}

Nas Ciências Humanas, mais especificamente na Educação, muitos pesquisadores se debruçaram em estudar o lúdico, dando ênfase às brincadeiras, aos jogos, ao teatro, à música e a outros elementos que fazem parte, ou pelo menos deveria fazer, dos cursos de formação de educadores.

As publicaçôes que têm como foco o lúdico não se tornaram ultrapassadas, pois ainda vêm possibilitando a muitos educadores (re)formularem sua prática pedagógica e, dessa forma, criarem diversas alternativas nos espaços-tempos escolares de modo que permita à criança experimentar as singularidades do mundo infantil.

Mesmo com várias possibilidades de aprofundamento sobre a dimensão lúdica, há resistência por parte da escola em vivenciar a ludicidade. Supostamente, por ser mais cômodo reproduzir o que é imposto pela sociedade capitalista a desenvolver um trabalho pautado na expressão criativa.

Nas sociedades capitalistas, as atividades lúdicas são consideradas irrelevantes ou de pouco valor, assumindo, frequentemente, um significado que exprime oposiçấo ao trabalho e vinculação ao ócio. Como consequência, o brincar vem perdendo seu espaço na infância.

Podemos dizer que a infância é hoje o período da vida em que se fica entalado entre a obrigação e o prazer, entre o reino da escola e o reino lúdico. E a nossa conformaçáo social tende a nos empurrar cada vez mais para dentro desse 'reino escola', onde 
imperam os valores da sociedade neoliberal: racionalidade, produtividade, eficiência, eficácia, competitividade, sucesso financeiro (OLIVIER, 2003, p. 18).

Para manter os valores da sociedade neoliberal, o sistema capitalista impóe um ritmo que leva à diminuição ou, até mesmo, à extinção dos momentos lúdicos, pois qualquer atividade que fuja ao controle e à organização da escola, se mostra como ameaçadora e improdutiva. Ao refletir sobre o brincar, Debortoli argumenta que,

a escola, preocupada em formar indivíduos úteis, moralmente disciplinados e tecnicamente preparados para o trabalho, buscou esvaziar as tradiçóes, a história dos povos e formá-los para uma nova sociedade, sociedade científica, tecnológica, industrial. Brincadeira na escola, só se tiver uma utilidade clara: domar o caráter, aprender e competir, compreender que nem todos vencem, desenvolver habilidades e comportamentos, auxiliar outras aprendizagens escolares, aliviar tensóes de aulas chatas e sem significado para as crianças (2006, p. 84).

Reflexo dessa concepção capitalista é constatado quando se verifica que o brincar é sugerido em muitas práticas pedagógicas apenas como pretexto e instrumento para o ensino de conteúdos, o que pode conduzir o lúdico a uma função estritamente utilitária (WAJSKOP, 2005; KISHIMOTO, 2009).

Quando há preocupação excessiva do professor em utilizar a ludicidade com o objetivo de apenas "transmitir" determinado conhecimento, atividades prazerosas se transformam em exercícios estéreis e sem sentido, tanto para o professor que as propóe, quanto para a criança que as vivencia.

Pudemos constatar na pesquisa de campo que algumas práticas ainda reproduzem essa concepçáo, pois, ao perguntar 
à professora Margarida se e como trabalha a ludicidade em suas aulas, ela afirma que o faz "[...] de forma que venha a desenvolver o intelecto da criança, com exercícios que exijam o raciocínio, acompanhando outros tipos de atividade como a leitura e a escrita".

Contrariamente a essa visão, Pereira e Bonfim ressaltam que o lúdico na escola deve ser utilizado como "um fim em si mesmo e não como um meio para alcançar os objetivos didáticos" (2009, p. 298), pois, independente do objetivo estabelecido pelo professor, a experiência lúdica propicia à criança o desenvolvimento e a aprendizagem que muitas outras ocupaçóes, até aparentemente mais sistematizadas, não propiciariam com grande eficácia. Brincar e aprender não devem estar em polos opostos, já que brincando a criança também aprende.

As brincadeiras contribuem para o desenvolvimento da mente imaginativa e da espontaneidade das açôes. De acordo com Vygotsky (2007), elas são igualmente importantes para ativar as funçóes cognitivas superiores tais como compreender, deduzir, analisar e generalizar, constituindo, assim, a base para a ampliação da criatividade. $\mathrm{O}$ autor aponta o brincar como uma atividade importante da infância, que possibilita a inserção da criança na cultura.

A ludicidade, além do aporte metodológico que oferece ao educador, permite benefícios pessoais como o estímulo à criatividade, à imaginação, à expressividade, à fantasia, ao autoconhecimento e ao cuidar de si. Sobre o processo de criação na brincadeira, Vygotsky (2009) explica que

A brincadeira da criança não é uma simples recordação do que vivenciou, mas uma reelaboração criativa de impressóes vivenciadas. É uma combinação dessas impressóes e, baseadas nelas, a construção de uma realidade nova que responde às aspiraçóes e aos anseios da criança. Assim como na brincadeira, o ímpeto da criança para criar é a imaginação em atividade (p. 17).

Ludicidade e

formação da crianç

no primeiro ano do

ensino fundamental

(n)

$$
\text { (1) }
$$


O brincar é inerente à rotina da criança, mesmo em momentos não autorizados pelo adulto. Diferentes situaçóes e objetos podem se configurar como elementos potencializadores da ludicidade. É o que observamos em uma das turmas do primeiro ano do Ensino Fundamental ao registrar o diálogo de duas crianças brincando com uma tesoura vermelha.

Rafael: Olha só a minha moto. Ela pode correr, andar devagar, andar para trás [...] o que eu quiser ela faz. O bom é que eu sou o piloto e posso fazer tudo isso. Só não posso correr muito para não machucar.

(Neste momento, a professora percebe que as duas crianças estáo conversando durante a sua explicaçáo e aproxima-se).

Gabriela: Esconde, esconde a moto. A policial vai ver que você está sem capacete.

Rafael: $\mathrm{O}$ que é que tem, se ela vê que eu estou sem capacete?

Gabriela: Ela vai te multar e tomar sua moto.

Rafael: É mesmo! (Registros Extraídos do Diário de Campo).

Vygotsky (2009), um dos grandes estudiosos da imaginação infantil, afirma que o brincar é uma atividade essencialmente criadora, em que a fantasia e a realidade interagem na produção de novas possibilidades de interpretação, de expressão e de ação pela criança, assim como em novas formas de desafios entre criança/criança, criança/ adulto, criança/objeto. Para o autor, existem duas modalidades básicas de impulsos na conduta tipicamente humana: o impulso reprodutor ou reprodutivo e o impulso combinador. $\mathrm{O}$ primeiro impulso está vinculado à memória, enquanto o segundo está relacionado à criatividade. 
$\mathrm{Na}$ brincadeira registrada acima, percebemos como esses dois tipos de impulsos se intercalam. Em certo momento, as crianças transpóem os conhecimentos das leis de trânsito para a brincadeira, comparando a professora a uma figura que pode punilos por descumprir uma regra instituída para o momento de aula.

Como vimos até aqui, são inúmeros os benefícios da atividade lúdica. A brincadeira, por exemplo, pode auxiliar a criança a criar noçóes de regras, de espaço e de lateralidade, além disso, lhe dá oportunidades para entender as situaçóes vividas e enfrentadas em seu cotidiano. Enquanto a criança brinca, sua atenção está centrada na atividade em si, e náo em seus resultados ou efeitos, o que a leva a experimentar as mais profundas emoçóes e os mais íntimos pensamentos.

\section{A CRIANÇA DO PRIMEIRO ANO DO ENSINO FUNDAMENTALEAEXPERIÊNCIALÚDICA: POSSIBILIDADES E DESAFIOS}

A rotina escolar das três turmas investigadas possui formas de organizaçáo semelhantes, embora haja variaçôes na intensidade e no ritmo da realizaçáo das tarefas. Algumas professoras, preocupadas em acelerar o ritmo de atividades por dia, acabam deixando algumas crianças que náo conseguem acompanhar a proposta para trás, levando-as a abandonarem suas atividades incompletas para atender à próxima solicitação. Resultados semelhantes são encontrados na pesquisa de Sant'Ana (2007) quanto ao ritmo diário das atividades.

\footnotetext{
Algumas professoras conseguem impor um ritmo mais veloz, frequentemente, abandonando algumas crianças, lentas, para trás, mediante um controle rígido das manifestaçóes dos alunos. Podemos dizer que é uma diferença de grau e não de espécie, ou seja, os conteúdos são praticamente os mesmos, mas a forma como são dados e a dinâmica interacional entre professores e alunos, e deles entre si, estabelecem a diferença (p. 40).
} 
No primeiro ano do Ensino Fundamental, há um fluxo contínuo de trocas de atividades xerocadas e, principalmente, mimeografadas. Isso ocorre tanto entre as professoras da mesma escola, quanto entre professoras de escolas diferentes. A tentativa de manter a uniformidade na aplicação dessas atividades gera um nível significativo de preocupação e ansiedade nas profissionais e nas crianças. No decorrer das observaçóes, ficou claro que essa postura constitui um hábito arraigado no cotidiano escolar, podendo ser interpretada como atividade meramente mecânica, mas, também, não deixando de lado a hipótese de outros fatores, como cobranças por parte da Superintendência Regional de Ensino, da direção das escolas e dos próprios pais. Durante uma das observaçóes, a professora Orquídea apresenta essa questão:

Aqui é assim, se não der muita tarefa, os pais reclamam, a direção cobra. Eles acham que as crianças não estão estudando. Às vezes, tenho que virar noites rodando matrizes para dar conta de passar todo o conteúdo (Extraído do Diário de Campo).

Pesquisas como a de Richter (2006), levantam a mesma questão, mostrando que as folhas mimeografadas ocupam grande parte do tempo das atividades da criança, tendo como justificativa

a dificuldade enfrentada na realização de atividades diferenciadas na turma, o que, provavelmente, implicaria uma movimentaçáo mais presente e, com isso, o medo da perda do controle da turma e, consequentemente, da avaliaçáo dos outros profissionais da instituição. Atividades que exigem comportamentos mais contidos são mais fáceis para manter a organização (p. 95).

Essa situação foi comum durante a pesquisa, sendo percebido que o movimento corporal das crianças incomodava bastante as professoras, que, várias vezes, criavam ocupaçóes 
apenas para manter o controle da turma. Ainda com relação a essa preocupaçáo excessiva das professoras com as atividades mimeografadas, as falas registradas ilustram duas situaçóes ocorridas.

Professora Margarida: Nossa! Esqueci de trazer as atividades para colar no caderno das crianças. Eu vou ficar atrasada com relação às outras professoras. Quarta-feira, sem falta, eu trago. Você pode estar aqui na quartafeira para me ajudar a fazer isso?

Professora Orquídea: Por favor! Você poderia levar essas atividades na sala do mimeógrafo para serem rodadas? Já está chegando o Dia do Índio [...] (Extraído do Diário de Campo).

As folhas mimeografadas representam a maior parte do acervo didático utilizado, isso contribui para a falta estímulo à expressáo e à criação da criança, pois o processo criador, segundo Borba e Goulart (2006), “[...] é singular, no qual o sujeito deixa suas marcas, revelando seus encaminhamentos, ordenamentos e formas próprias de se relacionar com os materiais, com o espaço, com as linguagens e com a vida" (p. 51).

Nesse contexto de temporalidades assíncronas entre crianças e adulto, a ludicidade perde espaço, mesmo o professorado ciente que é uma atividade repleta de sentidos na infância.

$\mathrm{Na}$ atividade lúdica, o professor assume um papel fundamental nos processos de desenvolvimento e aprendizagem dos educandos, pois é ele quem vai mediar a construçáo do conhecimento, proporcionando à criança um ambiente rico de possibilidades expressivas e criativas.

Pôr em prática uma proposta lúdica exige do professor conhecimentos teóricos e práticos da ludicidade e envolvimento nas atividades; náo basta "deixar brincar", mas há que se estabelecer uma relação de troca contínua com os

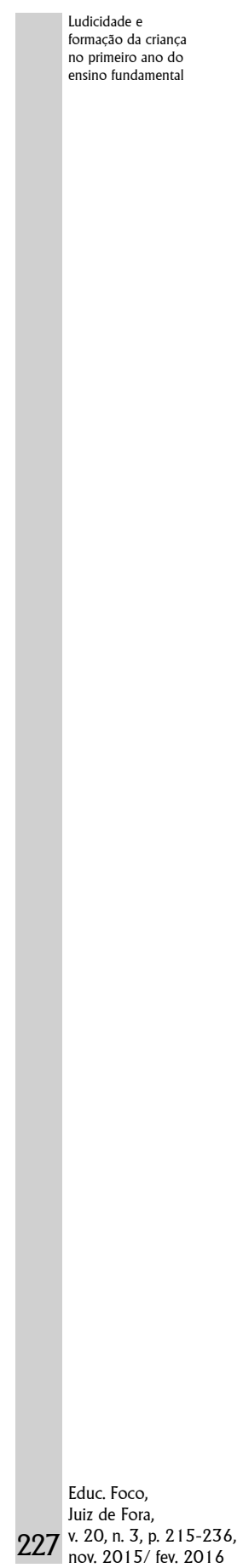


educandos. Essa proposta possibilitará o sentir, o pensar e o agir de todos os atores envolvidos no cotidiano da sala de aula, porque, além da educação que privilegie o ser humano em sua integralidade, é possível aquela que dê sentidos ao processo de construção da aprendizagem.

Durante as atividades lúdicas, as dimensóes cognitiva, afetiva e motora da criança são trabalhadas. Vygotsky (2007) aponta para essa interação, mostrando a importância do ato de brincar e suas consequências para o desenvolvimento da criança. "A criança, ao querer, realiza seus desejos. Ao pensar, ela age. As açôes internas e externas são inseparáveis: a imaginaçáo, a interpretação e a vontade são processos internos conduzidos pela ação externa" (p. 119).

Ainda nesse sentido, Negrine (1995) argumenta o quanto é fundamental que os professores trabalhem não apenas os aspectos cognitivos dos seus educandos, pois, por meio também das emoçóes e dos movimentos, a criança sistematiza grande parte da aprendizagem.

Toda experiência que a criança obtém em seu corpo, através das brincadeiras, serve de alavanca ao processo de desenvolvimento mental. Através da brincadeira, a criança aprende, internaliza novos comportamentos, verbaliza, entra em comunicação com os demais e, consequentemente, se desenvolve (p. 9).

Por caminhos diferentes, Tardif (2005) se aproxima dessa mesma concepção de não reduzir os saberes, "exclusiva ou principalmente, a processos mentais (representaçóes, crenças, imagens, processamento de informaçóes, esquemas etc.) cujo suporte é a atividade cognitiva dos indivíduos" (p. 11). O autor sinaliza que, apesar de vários movimentos contrários a essa visão mentalista, essa concepção de conhecimento ainda é predominante na educação.

As atividades lúdicas são possibilidades de modificar essa visão mentalista; assim, não devem ser vistas pela escola como 
atividades disciplinadoras, utilitaristas, recompensatórias ou simples passatempo. Trabalhar ludicidade em sala de aula implica proporcionar aos educandos uma aprendizagem prazerosa, dinâmica, significativa, enfim, de corpo inteiro, o que não compromete a aquisição dos conteúdos curriculares.

Além dos vários benefícios produzidos na ação lúdica, o ato de brincar é conferido como um direito da criança, como forma particular de expressão, pensamento, interação, movimento e comunicação infantil, como apontam alguns documentos, a exemplo o Estatuto da Criança e do Adolescente, aprovado pela Lei no 8.069, de 13 de julho de 1990: "II. Do direito à liberdade, ao respeito e à dignidade. Art. 16 - IV brincar, praticar esportes e divertir-se" (BRASIL, 1990).

A ludicidade está tão atrelada à infância que, em diversos momentos da observação da prática pedagógica, foi percebido que, mesmo as professoras não propiciando a brincadeira durante as aulas, as crianças criam estratégias para burlar a ordem e ter garantido o direito de brincar.

Brinquedos escondidos na mochila e brincadeiras durante as aulas são artimanhas utilizadas pela turma da professora Orquídea.

Quando eu os vejo brincando, escondem rapidinho dentro da mochila e em seguida pegam novamente, pensando que estáo me fazendo de boba. $\mathrm{Na}$ verdade, náo tem como a criança nos enganar. Eu já conversei com os pais na reunião, as crianças podem trazer o brinquedinho todos os dias. Não tem problema, mas devem brincar apenas na hora do recreio (Entrevista realizada em 24/06/2009).

Ao receber os educandos de seis anos no Ensino Fundamental, tenham eles frequentado ou não a Educação Infantil, é importante perceber que continua a necessidade de a criança experienciar a ludicidade na prática pedagógica. Refletir sobre essa temática é, também, pensar sobre os

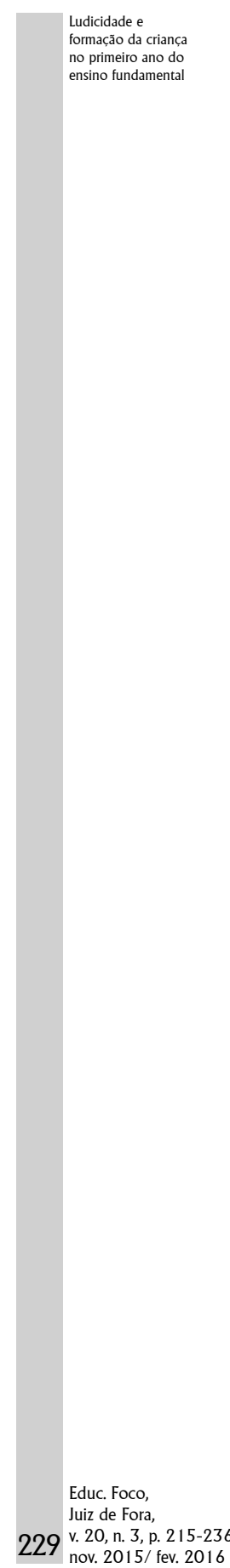


espaços-tempos que têm sido destinados à vivência da infância na escola.

Será que as práticas escolares da escola contemporânea têm dado espaço para a fruição das atividades criadoras? Têm possibilitado experiências que levem a um crescimento cognitivo, afetivo e motor? Acreditamos que, desde muito cedo, as crianças têm perdido este espaço de experienciar novas formas de ver o mundo, de inverter a ordem, de combinar cores. Isso nos leva a crer que ainda estamos distantes de uma educação que possibilite uma formação integral do ser humano.

\begin{abstract}
Transportando esta reflexão para a escola, percebemos a necessidade de se planejar a estruturação do ambiente escolar. Se for estruturado adequadamente, pode desempenhar um decisivo papel na promoção do desenvolvimento infantil. Para planejar essa estruturação, somos, mais uma vez, obrigados a ampliar o raio de abrangência da reflexão da prática pedagógica (GALVÃO, 1995, p. 101).
\end{abstract}

Wallon (2007), ao apontar a necessidade de uma reestruturação no ambiente escolar, não se refere apenas aos aspectos do ambiente físico, mas à organização dos tempos destinados à cultura lúdica, à preparação dos educadores para lidar com a criança, às propostas curriculares adequadas a cada faixa etária, à formação inicial e continuada dos professores, aos materiais didáticos e aos inúmeros outros agentes que podem contribuir para uma educação escolarizada que, efetivamente, forneça elementos para uma educaçáo da pessoa completa. Uma formação em que todos os aspectos afetivos, cognitivos e motores sejam considerados na escola.

\section{REVISTANDO ALGUMAS PONDERAÇÓES}

Este trabalho permitiu-nos apontar fragilidades estruturais e pedagógicas que a escola contemporânea 
apresenta ao ter que aderir à proposta do governo de ampliação do Ensino Fundamental de oito para nove anos de duraçáo e a lacuna existente entre o que propóe a lei e o que ocorre nos espaços-tempos escolares.

Nas escolas investigadas, pudemos detectar diversos problemas como falta de espaço físico apropriado às especificidades da infância; mobiliário inadequado; pouca informaçáo sobre a ampliação do ensino obrigatório tanto por parte das professoras, quanto dos pais, crianças e equipe diretiva; ausência de parquinho e de outros ambientes para a brincadeira; predomínio das atividades cognitivas em detrimento das expressivas; e os poucos momentos autorizados pelo adulto para vivenciar a ludicidade. Isso revela que permanecem problemas, os quais, segundo as Orientaçóes do Ministério da Educação (BRASIL, 2006), deveriam ser sanados, com prioridade, até 2010. Essa realidade é encontrada, também, em outros estados brasileiros, com um agravante mais sério: a inclusão de crianças de cinco anos no Ensino Fundamental.

Dentre os vários aspectos que poderíamos focar, destacamos a importância da ludicidade para a vivência da infância escolarizada. Privar a criança de exercer essa atividade na escola é ir de encontro a seu mundo divertido e imaginário, à sua fantasia e à sua criatividade. Na brincadeira, a criança socializa, compartilha com os seus pares a situaçáo vivida, é desafiada, aprende a lidar náo apenas com os sentimentos e situaçóes que propiciam o prazer, mas com situaçóes de conflito e inesperadas que também favorecem o pensamento, a reflexão, a autonomia, a identidade e a expressão.

Mais que garantir um maior número de crianças matriculadas na escola, é fundamental que se forneça a elas uma educação de qualidade, permitindo-lhes vivenciar a plenitude da infância com todas as potencialidades que a ludicidade desperta.

A vivência da ludicidade na escola é a possibilidade de uma aprendizagem que efetivamente chegue à criança, que faça
Ludicidade e

formação da criança

no primeiro ano do

ensino fundamental 
parte do seu mundo, das suas fantasias e da sua imaginação, que auxilie seu desenvolvimento, que lhe permita brincar, expressar-se, criar e movimentar-se. Como destacamos durante este texto, a ludicidade, nessa visão mais ampla, permite à criança vivenciar a educação institucionalizada de maneira espontânea neste momento singular de sua vida, a infância.

Em nenhum momento, quisemos desconsiderar que a ampliação do ensino obrigatório brasileiro foi um marco significativo nos processos de escolarização; o que nos propusemos a analisar é que muito ainda se deve discutir e problematizar quanto às questóes relativas às garantias mínimas de qualidade para a permanência das crianças de seis anos na escola.

De acordo com pesquisas de Bolsi (2006) e Correa (2007), há pouco espaço para as práticas lúdicas na Educação Infantil e no primeiro ano do Ensino Fundamental. Isso nos leva a deduzir que esse problema intensifica-se nos outros anos de escolarizaçáo, como naqueles em que as crianças de sete a dez anos estáo inseridas.

Para que a proposta de ampliação do ensino obrigatório ocorra efetivamente com qualidade, é fundamental o fortalecimento de açóes governamentais e coletivas, envolvendo pesquisadores, professores, gestores e demais profissionais da educação. Fazem-se necessárias condiçóes apropriadas para formação inicial e continuada dos professores, reestruturação do espaço físico e da organização dos tempos-espaços escolares, entre outras mudanças. Receber essas crianças de seis anos no Ensino Fundamental significa, ainda, a necessidade de investimento no campo da ludicidade, haja vista que a brincadeira é uma das formas fundamentais de desenvolvimento humano.

Expostas essas questóes, aponta-se que, apesar de ainda se dar pouco valor ao lúdico nas sociedades capitalistas, e, inclusive, na escola, é fundamental a vivência desses aspectos para a formação integral da criança. 
A ludicidade na escola é a possibilidade de uma aprendizagem que efetivamente chegue à criança, que faça parte do seu mundo, das suas fantasias e da sua imaginação, que auxilie seu desenvolvimento, que permita ao seu corpo brincar, se expressar, criar e movimentar-se.

\section{REFERÊNCIAS}

BOLSI, Miriam Terezinha. Concepçóes de corporeidade de professores da primeira série do Ensino Fundamental possibilidades, limites e implicaçóes. 2006. 123p. Dissertação (Mestrado) - Programa de Pós-Graduação em Educação, Faculdade de Educação, Universidade do Oeste de Santa Catarina, Joaçaba, 2006.

BRASIL. Ministério da Educação. Lei no 8.069, de 13/07/1990. Dispóe sobre o Estatuto da Criança e do Adolescente.

- Lei de Diretrizes e Bases da Educação Nacional 9.394/96. Brasília: MEC, 1996.

. Lei no 11.274, de 06/02/2006. Altera a redação dos artigos 29, 30, 32 e 87 da Lei no 9.394, de 20 de dezembro de 1996, que estabelece as diretrizes e bases da educação nacional, dispondo sobre a duração de 9 (nove) anos para o Ensino Fundamental, com matrícula obrigatória a partir dos 6 (seis) anos de idade.

.Ensino Fundamental de nove anos: orientaçóes para a inclusão da criança de seis anos de idade. In: BEAUCHAMP, Jeanete; PAGEL, Sandra Denise; NASCIMENTO, Aricélia Ribeiro do. Brasília: FNDE, Estação Gráfica, 2006.

CORREA, Bianca Cristina. Crianças aos seis anos no Ensino Fundamental: desafios à garantia de direitos. In: REUNIÃO DA ANPED, 30., 2007, Caxambu. Anais... Caxambu, GT 07, CD-ROM [ISBN 85-60316-01-9]. p. 1-17, 2007.
Ludicidade e

formação da crianç

no primeiro ano do

ensino fundamental 
DEBORTOLI, José Alfredo Oliveira. As crianças e a brincadeira. In: CARVALHO, Alysson; SALLES, Fátima; GUIMARÁES, Marília (Org.). Desenvolvimento e aprendizagem. 2. ed. Belo Horizonte: Ed. da UFMG, p. 77-88, 2006.

KISHIMOTO, Tizuko. Educação Infantil no Brasil e no Japão: acelerar o ensino ou preservar o brincar. Revista Brasileira de Estudos Pedagógicos, Brasília, v. 90, n. 225, p. 449467, maio/ago. 2009.

LUCKESI, Cipriano Carlos. Educação, ludicidade e prevenção das neuroses futuras: uma proposta pedagógica a partir da Biossíntese. In: LUCKESI, Cipriano Carlos (Org.) Ludopedagogia - Ensaios 1: Educação e Ludicidade. Salvador: Gepel, Vol. 1, p. 9-41, 2000. . Ludicidade e atividades lúdicas: uma abordagem a partir da experiência interna. In: PORTO, Bernadete de Sousa (Org.). Ludicidade: o que é mesmo isso? Salvador: Universidade Federal da Bahia, Faculdade de Educação, Programa de Pós-Graduação em Educação, GEPEL, v. 2, p. 22-60, 2002.

NEGRINE, Airton. Concepçóes do jogo em Vygotsky: uma perspectiva psicopedagógica. Movimento, Porto Alegre: Prodil, ano 2, n. 2, p. 6-23, jun. 1995.

OLIVIER, Giovanina Gomes de Freitas. Lúdico na escola: entre a obrigação e o prazer. In: MARCELLINO, Nelson C. (Org.). Lúdico, educação e educação física. 2. ed. Ijuí: Unijuí, p. 15-24, 2003.

PEREIRA, Lucia Helena Pena. Corpo e psique - da dissociação à unificação algumas implicaçóes na prática pedagógica. REUNIÂO DA ANPEd, 29., 2006, Caxambu. Anais... Caxambu, GT 20, p. 1-17. CD-ROM [ISBN 8560316-01-9]. p. 1-17, 2006.

; BONFIM, Patrícia Vieira. Brincar e aprender: um novo olhar para o lúdico no primeiro ano do Ensino Fundamental. Educação, Santa Maria: Centro de Educação da 
Universidade Federal de Santa Maria, ano 7, v. 34, n. 2, p. 295-310, maio/ago. 2009.

RICHTER, Leonice Matilde. Movimento corporal da criança na Educação Infantil: expressão, comunicação e interação. 2006. 174p. Dissertação (Mestrado)-Programa de Pós-Graduação em Educação, Universidade Federal de Uberlândia, Uberlândia, 2006.

SANT'ANA, Ruth Bernardes. Rotina Escolar na primeira série do Ensino Fundamental. In: PEREIRA, Lucia Helena P. OLIVEIRA, Wanderley Cardoso de (Orgs.). Práticas educativas: discurso e produção de saberes. Rio de Janeiro: Epapers, p. 31-61, 2007.

TARDIF, Maurice. Saberes docentes e formação profissional. 5. ed. Petrópolis, RJ: Vozes, 2005.

VYGOTSKY, Lev. S. A formação social da mente: o desenvolvimento dos processos psicológicos superiores. 7. ed. Sáo Paulo: Martins Fontes, 2007.

- Imaginação e criação na infância: ensaios psicológicos. São Paulo: Ática, 2009.

WAJSKOP, Gisela. Brincar na pré-escola. São Paulo: Cortez, 2005.

Data de recebimento: agosto de 2014

Data de aceite: junho de 2015 